\title{
Identifying essential ecological factors underpinning the development of a conservation plan for the Endangered Australian tree Alectryon ramiflorus
}

\author{
Peter J. Brown, Kevin R. Wormington and Philip Brown
}

\begin{abstract}
Reintroduction of rare and threatened species often fails to yield quantifiable conservation benefits because insufficient attention is focused on the species' habitat requirements and biology. We demonstrate the value of such data in informing a recovery plan for Alectryon ramiflorus S.Reyn. (Sapindaceae), a tree species endemic to a region on the southern coast of Queensland, Australia. When the species was categorized as Endangered on the IUCN Red List in 1997 the total known population consisted of only 26 adult plants, in five disjunct populations in remnant patches of native vegetation. Analysis of vegetation type, soil chemistry and composition data comparing remnant patches with and without $A$. ramiflorus revealed that the species is not restricted to a specific soil type but prefers sites with relatively fertile soil and a more complex vegetation structure. The species is cryptically dioecious, displays asynchronous flowering between individuals, and requires insectvectored pollination. The low rate of seedling production recorded within individual patches was attributed to the scarcity of trees of both genders, asynchronous flowering of individual trees and, in smaller patches, a sparse population of pollinating insect species. Successful reintroduction of $A$. ramiflorus will require consideration of these aspects of demographic success. The findings highlight the importance to species recovery plans of the knowledge of habitat requirements, interspecific relationships and critical dependencies, as well as species reproductive biology.
\end{abstract}

Keywords Conservation plan, dioecious, essential ecological factors, fragmentation, frugivory, microphyll, pollination, translocation

\section{Introduction}

ore than $20 \%$ of plant species are threatened with ex1 tinction because of unprecedented anthropogenic habitat disturbance and destruction (Brummitt \&

Peter J. Brown (Corresponding author), Kevin Wormington and Philip Brown CQ University, Locked Bag 3333, Bundaberg, QLD 4670, Australia

E-mail p.j.brown@cqu.edu.au

Received 12 June 2014. Revision requested 27 August 2014.

Accepted 21 November 2014. First published online 25 February 2015.
Bachman, 2010; IUCN/SSC, 2013). Conserving biodiversity in situ is the ideal scenario but is often not practicable (Godefroid et al., 2011). Reintroduction of threatened species into the wild is a common component of species recovery plans (IUCN/SSC, 2013; Ma et al., 2013). The success of such projects remains nominal, however, as a result of low survival rates and fecundity (Godefroid et al., 2011). Reintroductions may be improved by focusing increased attention on the species' biology and habitat requirements (Godefroid et al., 2011). IUCN principles for translocation include biological feasibility: basic knowledge of the candidate species' biotic and abiotic habitat requirements, interspecific relationships and critical dependencies, and its biology (e.g. seasonality, phenology and dispersal; IUCN/ SSC, 2013).

Alectryon ramiflorus S.Reyn (Sapindaceae) is a rare, narrowly endemic sub-tropical tree, confined to a number of remnant patches near Childers, on the southern coast of Queensland, Australia. It was first categorized as Endangered on the IUCN Red List in 1997, and the following year as Endangered $\mathrm{B} 1+2 \mathrm{C}$ (WCMC, 1998). At that time the population comprised 26 adult plants and 45 seedlings in five remnant patches in a landscape otherwise characterized by intensive agricultural production (Barker \& Barry, 2003) but several of the adults and most seedlings subsequently died from drought. The known population in 2013 comprised 26 plants (adults and saplings) in six remnant patches. A species recovery plan highlighted the lack of scientific knowledge about the species (Barker \& Barry, 2003) and was supported by the only previous study of the species, which recommended further research to better understand its habitat requirements, reproductive biology and genetics, and propagation methods (Van Kampen, 2001). In 2013 efforts commenced to address tenets of the recovery plan and prepare for rehabilitation of the species and translocation to new areas.

As preparation for the recovery of other threatened tree species, researchers have employed detailed physical ecological studies to assess the species' biotic and abiotic habitat requirements. For example, Aerts et al. (2009) recorded environmental data and studied vegetation profiles in plots located near a focal tree of the threatened native species Dalbergia oliveri Gamble ex Prain (Fabaceae) to plan the strategic planting of the species. Using indicator species that showed unique responses to environmental gradients, 
despite human disturbance, they found that the tree communities varied according to edaphic changes, although $D$. oliveri itself had wide ecological amplitude. No direct differences in site suitability were detected and the species was assessed to be suitable for reintroduction to a range of sites.

Much of the original habitat of A. ramiflorus and similar Araucarian microphyll vine forest species has been cleared for agriculture (Department of Environment and Heritage Protection, 2012). Remnants of the native vegetation exist in roadside patches or as individual plants in areas unsuitable for agriculture, and on the margins of higher quality agricultural land. Unlike A. ramiflorus, other microphyll vine forest species are more common in riparian gallery forest, and it is not uncommon to find isolated plants or small groups that have spread into other vegetation systems, such as dry sclerophyll forest. This suggests that $A$. ramiflorus may have more specific site requirements than the other species or may be sensitive to edaphic, environmental, community structure or other biological factors.

During 2013 we conducted a survey of the six remnant patches of A. ramiflorus in the Childers region, followed by quantitative data analysis. We examined dioecy, pollinators and seed dispersers. Our goals were based on five questions. (1) Is the species limited to disjunct patches because of the soil (e.g. chemical or edaphic factors)? (2) How does the species reproduce, and does incapacity to reproduce hinder seedling recruitment and population growth in the existing patches? (3) If A. ramiflorus does not have specific soil requirements, do habitat dynamics limit population growth? (4) Should rehabilitation of the species be via augmentation at the present sites or translocation of individual specimens to alternative sites within the species' indigenous range? (5) Can an understanding of habitat requirements be used to source hitherto unknown specimens and populations of $A$. ramiflorus?

\section{Study area}

When commencing this study the global population of extant A. ramiflorus comprised 26 adult and sapling plants in six remnant patches in the Childers region of Queensland, Australia (Fig. 1). The patches are narrow, with marked edge effects, and all are subjected to various combinations and levels of environmental degradation, including invasive plants, selective logging, erosion, livestock grazing, fire, drought and floods.

\section{Methods}

During May-August 2013 we surveyed 12 remnant sites containing microphyll vine forest species. Alectryon ramiflorus had been documented previously at six of these sites; at the other six some microphyll vine forest species were present

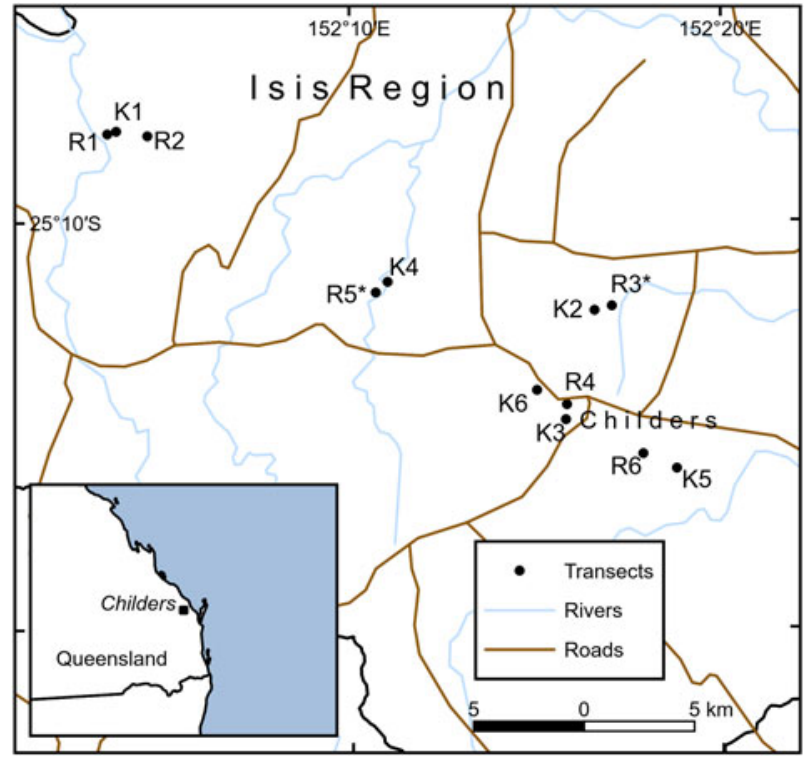

FIG. 1 Remnant patches of vegetation surveyed in the Isis region near Childers, Queensland, during 2013. The Isis Scrub, Araucarian microphyll vine forest, which grew on volcanic (ferrosol and chromosol) soil and also in the gallery forest of watercourses, once covered the middle to eastern portion of the map but the area is now cleared. With the exception of the $\mathrm{K}_{1}$ population, which is growing on a grey sodosol, remnants grow on marginal land on or near volcanic soil. Alectryon ramiflorus was found initially at six of the sites surveyed $(\mathrm{K})$. The species was found to be absent from six other sites $(\mathrm{R})$ but was subsequently discovered at two of these sites $\left(R^{\star}\right)$.

but $A$. ramiflorus was not known to occur. We compared vegetation forms and content, soil and other site characteristics. We also examined the reproductive biology of the species by observation and collection of data from flowering trees in remnant patches.

\section{Site surveys}

Each remnant site was inspected, and mapped using a geographical information system (GIS). We used geographical overlays of district soil (Bryant, 1997) and geology maps (Cranfield, 1994) in Quantum GIS v. 2.o.1 (Quantum GIS Development Team, 2014). All patches were sufficiently large to accommodate a $50 \times 10 \mathrm{~m}$ transect, and were characterized for presence or absence of $A$. ramiflorus and hoop pine Araucaria cunninghamii Aiton ex A. Cunn. All sites contained only microphyll and microphyll/notophyll vine forest \pm Araucaria cunninghamii (Department of Sustainability, Environment, Water, Population and Communities, 2013). The sites were denoted R1-R6 for patches with no known A. ramiflorus, and K1-K6 for the areas where A. ramiflorus had been described previously (Fig. 1). The reasons for the low number of study sites were the few known 
locations of A. ramiflorus and the overall scarcity of microphyll vine forest vegetation.

A transect was established in each patch and its position was recorded using a global positioning system. The vegetation structure and plant species assemblages were recorded following the methodology of Neldner et al. (2012) and Melzer (2004). Environmental variables, including the abundance and height of various vegetation classes, were measured (Table 1). The identity of each species was confirmed with reference to Stanley \& Ross (1983) or Harden et al. (2006).

A bulked soil sample, $10-30 \mathrm{~cm}$ deep, was collected from each of the $1250 \times 10 \mathrm{~m}$ transects for a comparative test of soil chemistry. The chemical and edaphic properties of each sample were analysed according to standard methods of the National Association of Testing Authorities.

We assessed the connectivity of each fragmented patch with adjacent remnant vegetation, using GIS and the rating system (0-5) of Eyre et al. (2011). A score of o denotes no connection, and a score of 5 denotes connection along $>75 \%$ of the perimeter. We also used GIS to measure the area of potential deposition of $A$. ramiflorus propagules by frugivores. A $600 \mathrm{~m}$ putative flight, or radius, in all directions via any evident protective corridors, was used to calculate the amount of vegetative cover within the circle.

\section{Statistical analysis}

The statistical package Primer 6 v. 6.1.12 (PRIMER-E, Ivybridge, UK) was used to assess differences in environmental data between sites. All data were square-root transformed with Euclidean distance. Bray-Curtis similarity was used to assess differences in plant assemblages between sites. Non-parametric multidimensional scaling was used to construct similarity diagrams of all sites, based on plant assemblages and environmental variables. Analysis of similarity (ANOSIM) was performed to examine patterns of statistical differences between the sites, based on soil type or the presence or absence of A. ramiflorus. BEST (Bio-Env + Stepwise procedure) analysis (Clarke et al., 2008) was then performed to assess the contribution of habitat variables (vegetation structure) and environmental variables (soil chemistry) that most accurately explained the significant differences in plant species assemblages between sites. Analysis of 99 random combinations yielded the top five variables.

Logistic regression, multiple regression, non-parametric tests, the Mann-Whitney $U$ test and Kruskal-Wallis ANOVA were undertaken using Statistica v. 7.1 (StatSoft Inc., Tulsa, USA) to compare environmental variables between presence/absence sites and soil type groups. Given the low number of sites, a marginal level of difference was set at $0.05<\mathrm{P} \leq 0.1$ in addition to the usual significance level of $\mathrm{P} \leq 0.05$.
TABLE 1 The environmental variables analysed to compare survey sites where Alectryon ramiflorus does and does not grow naturally.

\begin{tabular}{l} 
Environmental variables \\
\hline Abundance of native ground cover \\
Abundance of native shrubs \\
Abundance of native trees \\
Abundance of native vines \\
Abundance of weeds \\
$\%$ bare ground \\
Canopy (T1) mean height \\
Connectivity of patch with any adjacent remnant sites \\
$\%$ crown cover \\
Emergent mean height \\
Exchangeable sodium percentage \\
$\%$ litter (ground) \\
Lower shrub (S2) mean height \\
Seedlings $<0.5 \mathrm{~m}$ height, basal area per ha \\
Shrub (S1) mean height \\
Shrubs $>2 \mathrm{~m}$ height, basal area per ha \\
Shrubs $<2 \mathrm{~m}$ height, basal area per ha \\
Stem counts of plants $<5 \mathrm{~cm}$ DBH and $<1 \mathrm{~m}$ height, per ha \\
Stem counts of saplings $<5 \mathrm{~cm}$ DBH and $>1 \mathrm{~m}$ height, per ha \\
Stem $>5 \mathrm{~cm}$ DBH ( ${ }^{2}$ per ha) \\
Sub-canopy (T2) mean height
\end{tabular}

\section{Reproductive biology}

The duration of the flowering period of individual trees was assessed during December 2012-January 2014. Observations of flowers indicated dioecy and thus gender surveys were conducted during flowering.

To assess floral visitation by potential pollinators, flowering trees were observed for three 5-15 minute periods, on separate days. Where present, visiting insects were photographed at close proximity or, if necessary, trapped with sweep nets and identified to genus level.

Fruit consumption was monitored in the 2014 fruiting season (December-February) by direct observation and by automatically triggered infrared cameras (ScoutGuard, Molendinar, Australia). We recorded numbers of individuals of each species visiting fruiting trees, and frequency of visitation.

\section{Results}

\section{Survey results}

Our survey of remnant vegetation patches confirmed the presence of A. ramiflorus at the previously documented sites. We also assessed microphyll vine forest remnant vegetation on more marginal riparian land and on volcanic soils where A. ramiflorus had been described previously, and identified an undocumented area with a population of $A$. $r a-$ miflorus. This site was adjacent to the surveyed site $\mathrm{K}_{4}$. We 
made new records of $A$. ramiflorus at two additional sites, recording a sapling and a seedling at sites $\mathrm{R}_{4}$ and $\mathrm{R}_{5}$, respectively. Thus, the species was present at eight of the survey sites and absent from four.

The multivariate analyses (ANOSIM and nonparametric multidimensional scaling) and non-parametric tests (Mann-Whitney U Test and Kruskal-Wallis ANOVA) showed no differences in plant assemblages, vegetation structure or soil characteristics between site groups based on soil type. However, there were moderate to low differences between sites grouped by the presence or absence of A. ramiflorus (Fig. 2a,b). The plant assemblages differed (Global $\mathrm{R}=0.362, \mathrm{P}=0.032$ ) between sites where A. ramiflorus was present and sites where the species was absent (Fig. 2a), specifically vine (Global $\mathrm{R}=0.347, \mathrm{P}=0.028$ ) and weed (Global $\mathrm{R}=0.604, \mathrm{P}=0.006$ ) assemblages. The vegetation structure also differed (Global $\mathrm{R}=0.375$, $\mathrm{P}=0.016$ ) according to presence or absence of $A$. ramiflorus (Fig. 2b).

Non-parametric tests of absence and presence sites revealed differences in the soil $\mathrm{NO}_{3}$ content and four structural variables associated with above-ground cover: stem count $<_{5} \mathrm{~cm}$ diameter at breast height $(\mathrm{DBH})$ and $>_{1} \mathrm{~m}$ height per ha; stem count $<_{5} \mathrm{~cm} \mathrm{DBH}$ and $<_{1} \mathrm{~m}$ height per ha; area of coverage of shrubs $<2 \mathrm{~m}$ height per ha; percentage crown cover $(\mathrm{P}<0.048,<0.016,<0.048,<0.028$, $<0.008$, respectively). Logistic regression modelling showed that, for plant assemblages and soil values, measurements of soil $\mathrm{No}_{3}(\mathrm{P}=0.018)$ and percentage crown cover $(\mathrm{P}<0.002)$ were correlated, individually and as a whole $(\mathrm{P} \leq 0.001)$, between the 12 site groups. Soil copper content was also correlated with the presence of $A$. ramiflorus $(\mathrm{P} \leq \mathrm{0.017})$.

Multiple regression analysis (Table 2) of the site groups with and without $A$. ramiflorus revealed exchangeable sodium percentage (ESP) was inversely related to native vegetation crown cover and the abundance of native shrubs. Moreover, soil $\mathrm{NO}_{3}$ was inversely related to the abundance of shrubby weeds and native shrubs. BEST analysis of the ordination data of the plant assemblages and environmental measurements revealed correlations between the weed assemblages and vegetation structure but not between weeds and soil chemical variables (Table 3). The structural elements that were linked to the weed assemblages were associated with the cover provided by lower and highest vegetation layers. Similarly, the vine assemblages were correlated with the lower and highest vegetation canopy cover and also with some of the soil elements.

The discovery of the new A. ramiflorus population during the survey was serendipitous for recovery of the species. The site contains an actively spreading population of $192 \mathrm{~A}$. ramiflorus plants, including four significantly older parent trees adjacent to the riparian microphyll vine forest. The population is located in dry sclerophyll woodland and

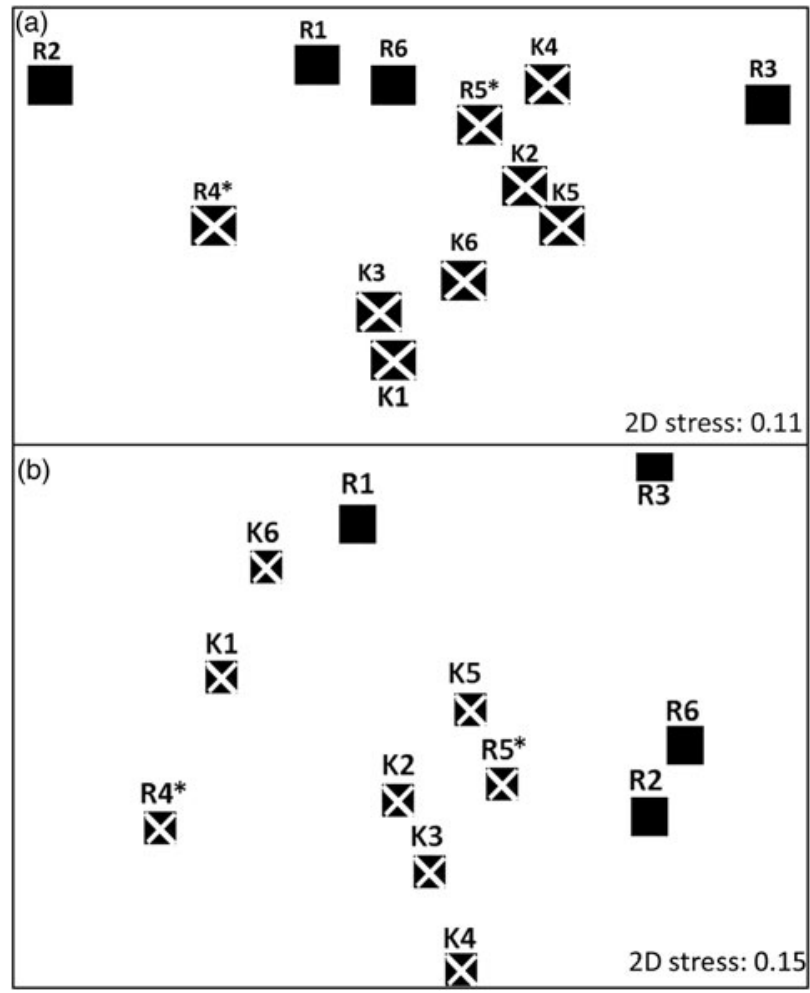

FIG. 2 Two-dimensional scaling diagrams representing the dissimilarities between the 12 sites of remnant vegetation. The low stress values indicate that the configurations are close to the actual dissimilarities. A. ramiflorus was initially present at six sites $(\mathrm{K}) \mathrm{C}$ and absent from six sites (R) a but single specimens were discovered subsequently at two more sites $\left(\mathrm{R}^{\star}\right) \mathbf{z}$.

(a) Comparison of plant assemblages (square root transformation; resemblance: S17 Bray Curtis similarity). Plant assemblages were significantly different (Global $R=0.362$, $\mathrm{P}=0.032$ ). (b) Comparison of vegetation structure (square root transformation; normalize, Euclidean distance). Structure was significantly different (Global $\mathrm{R}=0.375, \mathrm{P}=0.059$ ).

riparian vine forest on a podosol substrate. This area has been disturbed in the past by logging and contains an abundant population of weeds, principally Lantana camara L. and Ochna serrulata (Hochst.) Walp. The patch is well connected to remnant vegetation and, via the riparian zone, to a State Forest. The vegetation structure and soil fertility at the site are consistent with other sites where A. ramiflorus was present.

\section{Floral biology}

Our observations provide the first record that A. ramiflorus is cryptically dioecious. Female trees bear flowers that are morphologically hermaphroditic but functionally female (Plate 1a). Male trees bear morphologically and functionally male flowers (Plate $1 \mathrm{~b}$ ). All observed flowers were either fully male or fully female. Pollen transfer between male and female trees is therefore required for seed set. This 
TABLE 2 A single multiple regression analysis revealed models for each of three relationships: between crown cover and exchangeable sodium percentage (ESP); between native shrub abundance and ESP; and between abundance of weeds (shrubs) and native shrubs and soil $\mathrm{NO}_{3}$ (mg per kg).

\begin{tabular}{lcclll}
\hline Independent variable & Parameter estimate & Standard error & $\mathrm{P}$ & $R^{2}$ & Dependent variable \\
\hline Relationship between crown cover \& ESP & & & & \\
Intercept & 88.604 & 10.402 & $<0.000007$ & & \\
ESP & -6.409 & 2.228 & $<0.0164$ & 0.452 & Crown cover \\
Relationship between native shrub abundance \& ESP & & & \\
Intercept & 4.152 & 0.541 & $<0.000017$ & & \\
ESP & -0.258 & 0.116 & $<0.05$ & 0.33 & Native shrub abundance \\
Relationship between abundance of weeds & (shrubs) \& native shrubs \& soil NO $\mathbf{N}_{\mathbf{3}}$ (mg per kg) \\
Intercept & 8.015 & 0.484 & $<0.0001$ & & \\
$\mathrm{NO}_{3}$ (mg per $\left.\mathrm{kg}\right)$ & -0.407 & 0.177 & $<0.047$ & 0.369 & Weed (shrub) \& native shrub abundance (log) \\
\hline
\end{tabular}

TABLE 3 The effects of forest structure on weed assemblages, of soil nutrients on the growth of vine assemblages, and of vegetation structure on weed assemblages, analysed using the BEST procedure. In each case 99 permutations were run and the top five environmental variables were selected to explain the biological correlation patterns.

\begin{tabular}{|c|c|c|c|}
\hline Single variable run & Correlation & Top five variables run & Correlation \\
\hline \multicolumn{3}{|c|}{ Effect of forest structure on weed assemblages } & $(\mathrm{P}=0.02)$ \\
\hline $\begin{array}{l}\text { Stem count }<5 \mathrm{~cm} \mathrm{DBH} \mathrm{\&}<1 \mathrm{~m} \\
\text { height, per ha }\end{array}$ & 0.488 & $\begin{array}{l}\text { Stem count }<5 \mathrm{~cm} \mathrm{DBH} \&>1 \mathrm{~m} \text { height, per ha; stem } \\
\text { count }<5 \mathrm{~cm} \mathrm{DBH} \&<1 \mathrm{~m} \text { height per ha; seedlings } \\
<0.5 \mathrm{~m} \text { height, per ha; connectivity; } \% \text { bare ground }\end{array}$ & 0.569 \\
\hline $\begin{array}{l}\text { Stem count }<5 \mathrm{~cm} \mathrm{DBH} \mathrm{\&}>1 \mathrm{~m} \\
\text { height, per ha }\end{array}$ & 0.367 & $\begin{array}{l}\text { Stem count }<5 \mathrm{~cm} \mathrm{DBH} \&>1 \mathrm{~m} \text { height, per ha; stem } \\
\text { count }<5 \mathrm{~cm} \mathrm{DBH} \mathrm{\&}<1 \mathrm{~m} \text { height, per ha; \% crown } \\
\text { cover; connectivity; \% bare ground }\end{array}$ & 0.569 \\
\hline \multicolumn{3}{|c|}{ Effect of soil nutrients on the growth of vine assemblages } & $(\mathrm{P}=0.03)$ \\
\hline Zinc & 0.389 & $\begin{array}{l}\text { Calcium, boron, zinc, cation exchange capacity, cal- } \\
\text { cium cation } \%\end{array}$ & 0.601 \\
\hline Magnesium cation \% & 0.373 & Calcium, boron, zinc, calcium cation \% & 0.595 \\
\hline Calcium & 0.365 & & \\
\hline \multicolumn{3}{|c|}{ Effect of vegetation structure on weed assemblages } & $(\mathrm{P}=0.01)$ \\
\hline $\begin{array}{l}\text { Shrubs }<2 \mathrm{~m} \text { height, basal area } \\
\text { per ha }\end{array}$ & 0.390 & $\begin{array}{l}\text { T2; seedlings }<0.5 \mathrm{~m} \text { basal area per ha; shrubs }<2 \mathrm{~m} \\
\text { height, basal area per ha; \% litter; \% bare ground }\end{array}$ & 0.590 \\
\hline$\%$ Crown cover & 0.325 & $\begin{array}{l}\text { T2; seedlings }<0.5 \mathrm{~m} \text { per ha; shrubs }<2 \mathrm{~m} \text { height, } \\
\text { basal area per ha; } \% \text { bare ground }\end{array}$ & 0.580 \\
\hline $\begin{array}{l}\text { Seedlings }<0.5 \mathrm{~m} \text { height, basal } \\
\text { area per ha }\end{array}$ & 0.260 & & \\
\hline
\end{tabular}

finding is consistent with the conclusion of the previous study of this species (Van Kampen, 2001) that the lack of fruit development in single $A$. ramiflorus may result from lack of pollination.

Insects were observed as pollen foragers and potential pollination vectors. Pendant female flowers were observed to exude a drop of nectar, consistent with attraction of insect pollinators. The most common visitor to the flowers was the stingless bee Tetragonula carbonaria, and lepidopterans were observed occasionally. When pollen release was profuse at the sites $\mathrm{K}_{1}$ and $\mathrm{K}_{4}$, trees were visited predominantly by other bees, such as honey bees Apis mellifera and carpenter bees Xylocopa sp.

Flowering was observed to occur in month-long episodes from late spring to early summer but only in trees with a minimum DBH of $6 \mathrm{~cm}$. There was general synchrony in flowering between male and female trees when sufficient numbers of both were present. Fruit set did not occur in patches with isolated trees, asynchronous flowering, or failure of either male or female trees to flower.

\section{Frugivory}

The presence of small, brightly coloured, fleshy fruit was consistent with frugivory as the main system for seed dispersal. Little bronze cuckoos Chrysococcyx malayanus, Lewin's honeyeaters Meliphaga lewinii and ringtail possums Pseudocheirus peregrinus were observed eating ripe fruit. The high connectivity of site $\mathrm{K}_{4}$ to remnant vegetation, including the newly described site, is consistent with the site providing habitat for frugivorous species, thus facilitating 


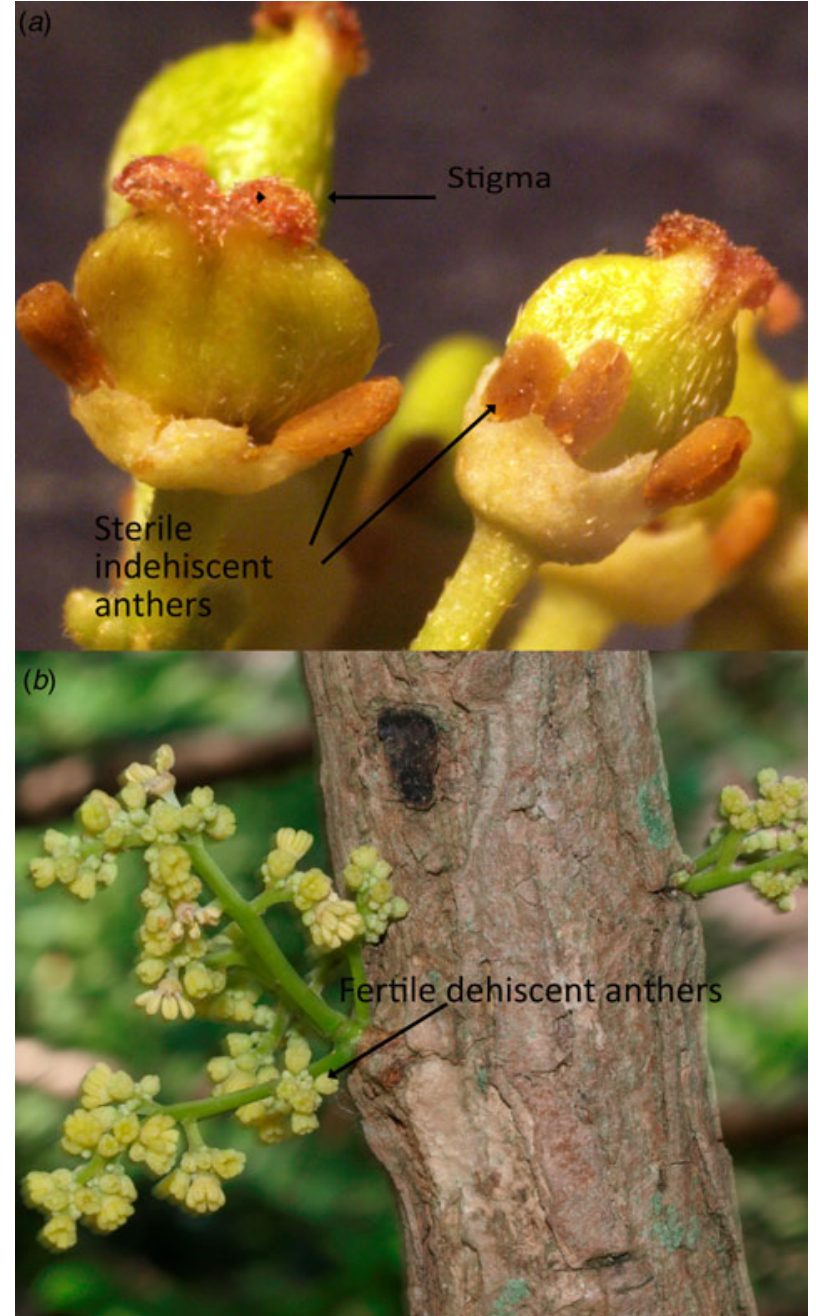

Plate 1 Flowers of cryptically dioecious Alectryon ramiflorus. (a) All female flowers present sterile indehiscent anthers to attract pollinators. (b) Male flowers present dehiscent anthers with fertile pollen.

dispersal of seeds and subsequent seedling recruitment for the expanding population.

\section{Discussion}

Only a small number of $A$. ramiflorus trees are known, in degraded, circumscribed, remnant microphyll vine forest habitat. Only two sites, including one newly identified, contain the range of adults and progeny that characterize an active population. The study was predicated on the hypothesis that occupied and unoccupied sites were differentiated by features such as soil qualities and vegetation assemblages. Multivariate analysis indicated that A. ramiflorus is not restricted to a specific soil type but prefers sites with relatively fertile soil.

Vegetation structural components such as crown cover and basal area affect levels of incident light, and this promoted weed proliferation in the most highly disturbed patches. This was most evident at the four sites where $A$. ramiflorus was absent, which were more severely disturbed and degraded, with a less complex vegetation structure and more weeds. The presence and absence sites also differed in the proliferation of native vines. Some macro and micronutrients (copper, zinc, nitrate) and one edaphic factor (cation exchange capacity) were found to influence the vegetation assemblages. At R1, R2 and R6 few native vines occurred because there was sparse canopy and sub-canopy to support their proliferation and dispersal. At the fourth site where $A$. ramiflorus was absent $\left(\mathrm{R}_{3}\right)$, low numbers of vines resulted from a sparsity of microphyll vine forest vegetation. Thus, a critical mass of microphyll vine forest vegetation favours proliferation of forest floor litter and nutrient recycling, which, with minimal disturbance, in turn perpetuates favourable growing conditions (Lázaro-Nogal et al., 2012). The richness of the forest in which $A$. ramiflorus grows stems from soil quality, which is augmented by the presence of complex forest.

The significant inverse relationship of $\mathrm{NO}_{3}$ with the abundance of shrubby weeds and native shrubs across the remnant sites may be a result of the proliferative effect of higher $\mathrm{NO}_{3}$ levels on upper canopy strata, which suppress the growth of lower strata. Furthermore, at $\mathrm{K}_{4}$, where the highest level of soil $\mathrm{NO}_{3}$ was found, possibly originating from an adjacent agricultural crop (Gabriel et al., 2012), weed shrubs were abundant but only two species dominated, and suppressed the growth of native shrubs. Exchangeable sodium percentage was found to be correlated with aspects of vegetation growth at site groups with and without A. ramiflorus, but variability as a result of exposure of some sites to floodwater deposition of dispersive sodium clays, and other factors influencing canopy cover development, make it difficult to conclude a significant role for exchangeable sodium percentage in influencing presence of $A$ ramiflorus.

At the eight sites where A. ramiflorus was present, barriers to seedling recruitment and population growth probably did not originate in the soil characteristics but in the individual patch size, its connectivity, and the type and variety of flowering plants present. These factors are likely to determine the rate of cross pollination, fruit set and fruit dispersal.

Identification of dioecy in A. ramiflorus provides an explanation for its current distribution that is consistent with the site assessment data, and has significant implications for the conservation of the species. Angiosperms with a dioecious breeding system may be more prone to extinction because of reduced mate assurance, and reliance on pollinators (Vamosi \& Vamosi, 2005). The dioecious crosspollination strategy may also be confounded by the failure of certain individuals to flower synchronously (cf. Renner et al., 2007). In the isolated, depauperate patches studied 
here, cross-pollination is improbable if the patch contains a single gender of one species and if the flowering time for both genders is asynchronous. The combination of dioecious flowers, with the female displaying showy sterile anthers to attract anthophilous insects, and asynchronous flowering means that habitat for pollinators must feature in a translocation plan for A. ramiflorus.

Ensuring effective frugivory must also be an integral part of such a translocation plan. In the newly described population adjacent to site $\mathrm{K}_{4}$, large trees such as Eucalyptus spp. and Corymbia spp. are crucial in providing perches and roosts for frugivorous birds, and shelter for frugivorous mammals such as possums. The placement pattern of trees in this population suggests many of them originated from seed excreted by birds perching on and roosting in the taller trees. These trees, along with other vegetation, form a valuable wildlife corridor for delivery of seed in fruit, which mimics past patterns where gene flow probably occurred overland, not only via gallery forest, subject to the movement of mammals and birds (Shapcott, 2002).

The presence of weeds such as L. camara (Verbenaceae) and O. serrulata (Ochnaceae) at the newly described site may have a deleterious effect on the general environment but has proven beneficial for the A. ramiflorus population. The plant mass may discourage primary industry, such as logging, and ingestion of L. camara is a significant cause of livestock morbidity and mortality in lantana-infested regions (Sharma et al., 2007). This has probably influenced land management decisions, with no grazing or land clearing at the site favouring establishment of $A$. ramiflorus seedlings. In addition, the flowers and fruit of L. camara and $O$. serrulata provide an abundant, out-of-season source of food for insects and frugivorous birds, sustaining populations that may also cross pollinate and distribute the seeds of $A$. ramiflorus. The value of weed species as hosts for important pollinators for rare and threatened plant species has been demonstrated (Carvalheiro et al., 2008).

These findings help to explain why the remnant populations of A. ramiflorus not only fail to expand but are declining steadily at all but two remnant sites. This rare plant species is at risk of extinction because its fragmented distribution means that pollination and seed delivery services, and therefore gene flow, are limited or absent. Our findings may contribute not only to the conservation of A. ramiflorus and other Araucarian microphyll vine forest species but also to the formulation of plans for the rehabilitation of other threatened plants.

Recovery plans that incorporate translocation of other rare and threatened plant species usually feature aspects of soil quality that will deliver suitable vegetative growth but they often place less emphasis on biotic habitat components. Our study documents for the first time key requirements for biological feasibility for a threatened dioecious tree species. For dioecious species threatened by loss of habitat in their historical range, translocation may require augmenting recipient sites that possess suitable capacity or may be rehabilitated to have suitable capacity. These sites should be interconnected by corridors and contain a mixture of flowering and fruiting species to support pollinators and seed dispersal species. This recommendation adds to the suite of factors to be considered when following IUCN guidelines for assessing biological feasibility for translocation of rare and threatened tree species.

\section{Acknowledgements}

We gratefully acknowledge the helpful advice and assistance of Isis Central Sugar Mill Co. Ltd., Sue Sargent (Burnett Mary Regional Group) and Fauna \& Flora International.

\section{References}

Aerts, R., Volkaert, H., Roongruangsree, N., Roongruangsree, U.T., Swennen, R. \& Muys, B. (2009) Site requirements of the endangered rosewood Dalbergia oliveri in a tropical deciduous forest in northern Thailand. Forest Ecology and Management, 259, 117-123.

B ARKer, M. \& B ARRY, S. (2003) Recovery Plan for the Isis Tamarind Alectryon ramiflorus 2003-2007. Report to Environment Australia, Canberra. Queensland Parks and Wildlife Service, Brisbane, Australia.

Brummitt, N. \& Bachman, S. (2010) Plants Under Pressure-A Global Assessment. The first report of the Sampled Red List Index for Plants. Royal Botanic Gardens, Kew, UK.

Bryant, M.J. (1997) Childers Area Soils. Natural Resources Map Series. Department of Natural Resources, Brisbane, Australia.

Carvalheiro, L.G., Barbosa, E.R.M. \& Memmott, J. (2008) Pollinator networks, alien species and the conservation of rare plants: Trinia glauca as a case study. Journal of Applied Ecology, 45, 1419-1427.

Clarke, K.R., Somerfield, P.J. \& Gorley, R.N. (2008) Testing of null hypotheses in exploratory community analyses: similarity profiles and biota-environment linkage. Journal of Experimental Marine Biology and Ecology, 366, 56-69.

Cranfield, L.C. (1994) $1: 250$ ooo geological series-explanatory notes. In Geological Survey of Queensland (ed. J.W. Beeston). Geological Survey of Queensland, Brisbane, Australia.

Department of Environment and Heritage Protection (2012) Regional Ecosystem Descriptions. Http://www.ehp.qld.gov.au/ ecosystems/biodiversity/regional-ecosystems/index.php [accessed 4 March 2014].

Department of Sustainability, Environment, Water, Population and Communities (2013) Species Profile and Threats Database. Http://www.environment.gov.au/cgi-bin/sprat/public/ sprat.pl [accessed 13 April 2013].

Eyre, T.J., Kelly, A.L., Neldner, V.J., Wilson, B.A., Ferguson, D. J., Laidlaw, M.J. \& Franks, A.J. (2011) BioCondition: A Condition Assessment Framework for Terrestrial Biodiversity in Queensland. Assessment Manual. Version 2.1. Department of Environment and Resource Management, Biodiversity and Ecosystem Sciences, Brisbane, Australia.

Gabriel, J.L., Muñoz-Carpena, R. \& Quemada, M. (2012) The role of cover crops in irrigated systems: water balance, nitrate leaching 
and soil mineral nitrogen accumulation. Agriculture, Ecosystems \& Environment, 155, 50-61.

Godefroid, S., Piazza, C., Rossi, G., Buord, S., Stevens, A.-D., Aguraiuja, R. et al. (2011) How successful are plant species reintroductions? Biological Conservation, 144, 672-682.

Harden, G.J., McDonald, B., McDonald, W.J.F. \& Williams, J.B. (2006) Rainforest Trees and Shrubs: A Field Guide to Their Identification in Victoria, New South Wales and Subtropical Queensland Using Vegetative Features. Gwen Harden Publishing, Nambucca, Australia.

IUCN/SSC (2013) Guidelines for Reintroductions and Other Conservation Translocations Version 1.o. IUCN Species Survival Commission, Gland, Switzerland.

Lázaro-Nogal, A., Matesanz, S., Gimeno, T.E., Escudero, A. \& Valladares, F. (2012) Fragmentation modulates the strong impact of habitat quality and plant cover on fertility and microbial activity of semiarid gypsum soils. Plant and Soil, 358, 213-223.

Ma, Y., Chen, G., Grumbine, R.E., Dao, Z., Sun, W. \& Guo, H. (2013) Conserving plant species with extremely small populations (PSESP) in China. Biodiversity and Conservation, 22, 803-809.

Melzer, R. (2004) A System for the Collection of Site Data. Environmental Protection Agency, Brisbane, Australia.

National Association of Testing Authorities, Australia Http://www.nata.com.au [accessed 3 December 2014].

Neldner, V.J., Wilson, B.A., Thompson, E.J. \& Dillewaard, H.A. (2012) Methodology for Survey And Mapping of Regional Ecosystems and Vegetation Communities in Queensland. Version 3.2. Updated August 2012. Queensland Herbarium, Queensland Department of Science, Information Technology, Innovation and the Arts, Brisbane, Australia.

Quantum GIS Development Team (2014) QGIS. Http://gis.org/ en/site/ [accessed 1 December 2014].
Renner, S.S., Beenken, L., Grimm, G.W. \& Ricklefs, R.E. (2007) Evolution of dioecy, heterodichogamy, and labile sex expression in Acer. Evolution, 61, 2701-2719.

Sнарсотт, A. (2002) Conservation genetics and ecology of the endangered rainforest shrub, Triunia robusta, from the Sunshine Coast, Australia. Australian Journal of Botany, 50, 93-105.

Sharma, O.P., Sharma, S., Pattabhi, V., Mahato, S.B. \& Sharma, P.D. (2007) A review of the hepatotoxic plant Lantana camara. Critical Reviews in Toxicology, 37, 313-352.

Stanley, T.D. \& Ross, E.M. (1983) Flora of South-eastern Queensland. Department of Primary Industries, Brisbane, Australia.

Vamosi, J.C. \& VAmosi, S.M. (2005) Present day risk of extinction may exacerbate the lower species richness of dioecious clades. Diversity and Distributions, 11, 25-32.

Van Kampen, T. (2001) Propagation of the Endangered tree species Alectryon ramiflorus by stem cuttings, and field observation of one season of flowering, fruiting and growth. Biology project. Central Queensland University, Rockhampton, Australia.

WCMC (World Conservation Monitoring Centre) (1998) Alectryon ramiflorus. In IUCN Red List of Threatened Species v. 2014.3. Http://www.iucnredlist.org [accessed 1 December 2014].

\section{Biographical sketches}

Peter Brown specializes in plant biology, the ecology of threatened species, science education, and plant pathology. KEviN WORMINGTON is an ecologist and is interested in the habitat requirements for conservation-listed flora and fauna. PHIL BROWN is a plant physiologist and is interested in the application of physiology to address questions in plant reproductive biology and propagation. 